\title{
Substance Use and Mental Illness among Women Admitted in a Rehabilitation Center in Jos, Nigeria: A 5-Year Profile
}

\author{
Nwoga $C N^{1}$, Dapap DD ${ }^{2}$, Armiya'u AY $Y^{3}$, Audu $\mathrm{MD}^{1}$, Goar $S G^{1}$, Mafai $D^{4}$, Jack $\mathrm{DB}^{5}$ \\ ${ }^{1}$ Department of Psychiatry, College of Medicine, University of Jos, Plateau state, Nigeria. \\ ${ }^{2}$ Department of Psychiatry, College of medicine, Bingham University, Jos, Plateau state, Nigeria. \\ ${ }^{3}$ Department of Psychiatry, Jos University Teaching Hospital. Jos, Plateau state, Nigeria \\ ${ }^{4}$ Psychology department, Quintessential Healthcare Center, Rayfield,, Jos, Plateau state, Nigeria \\ ${ }^{5}$ Department of Psychology, University of Jos, Jos, Plateau state, Nigeria \\ *Correspondence: Nwoga CN. Department of Psychiatry, College of Medicine, \\ University of Jos, Plateau state, Nigeria.
}

Article information

\begin{abstract}
Date Submitted: 20/5/2021.
Date Accepted: $\quad 17 / 6 / 2021$
\end{abstract}

Date Published: $16 / 7 / 2021$

\begin{abstract}
Substance use disorder are among the most common public health problems caused by using legal and/or illegal substances. Therefore, this study is aimed at reviewing a five-year profile of women admitted at a rehabilitation center in Jos, Nigeria for substance use and mental illness. This is a retrospective cross-sectional study carried out on 183 females admitted between 2012 and 2017 at a rehabilitation center in Jos, Nigeria. Data were analyzed using SPSS version 22. The mean age of the participants was 38.515.3 years. Almost half of the participants were within the age bracket of 20 - 29 years and married (45.9\%). Depressive disorder (36.1\%) was the commonest mental disorder in the studied participants. Among those abusing substances, multiple substance use (12.6\%) was the most prevalent with alcohol use disorder $(9.3 \%)$ the main diagnosis among those with substance use disorder. According to the result, almost half of the studied participants were young, married and educated females. Depression and multiple substance abuse with alcohol the main drug of abuse was a cause of concern in this population. This portrays significant health and economic consequences and the need for urgent action.
\end{abstract}

Keywords: Rehabilitation center; Substance Use Disorder; Mental Illness; Female.

\section{INTRODUCTION}

$\mathrm{S}^{\mathrm{u}}$ ubstance dependence in women is becoming increasingly prevalent. Generally, it is assumed that substance use in women often start in adolescence years like in the male counterparts. ${ }^{1,2}$ The number of drug users

How to cite this article

Nwoga CN, Dapap DD, Armiya'u AY, Audu MD, Goar SG, Mafai D. Substance Use and Mental Illness among Women Admitted in a Rehabilitation Center in Jos, Nigeria: A 5-Year Profile. J Biomed Res Clin Pract:2021;4(1):19-26. in Nigeria is estimated at 14.4 per cent or 14.3 million people aged between 15 and 64 years according to the results of the National Drug Use Survey. ${ }^{3}$ The data suggested that the 2018 prevalence of past year drug use

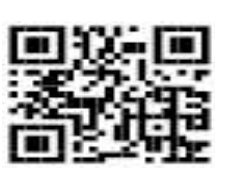

Access to the article

website: http://www.jbrcp.net

do: : https://doi.org/10.46912/jbrcp.224 
in Nigeria was more than twice the global average of 5.6 per cent. According to the survey, one in four of every drug user in Nigeria was a woman while one of five of high-risk drug users inject drugs. The report showed a gap in meeting the needs for treatment and care for people with drug use disorders even as close to 3 million Nigerians were living with some level of drug dependence. It highlighted extremely limited availability of drug counselling and treatment services in Nigeria. ${ }^{3}$ Globally, UNODC estimates that between 155 and 250 million people, or $3.5 \%$ to $5.7 \%$ of the population aged 15-64, had used illicit substances at least once in the previous year. Cannabis users comprises the largest number of illicit drug users (129-190 million people). Amphetamine-type stimulants are the second most commonly used illicit drugs, followed by opiates and cocaine. However, in terms of harm associated with use, opiates would be ranked at the top. ${ }^{4} \mathrm{~A}$ study in the United States of America has shown that $7.7 \%$ of males in comparison with $5 \%$ of females were drug abusers (the sex difference was lower than $3 \%$ documented previously). ${ }^{5}$ Also, almost 4.5 million women drink alcohol, 3.5 million abuse prescription drugs, and more than 3 million abused illicit drugs. ${ }^{5}$

The pattern of substance use varies according to culture of people, psychosocial factors, ${ }^{2}$ hence gender specific treatment are increasingly advocated. ${ }^{6}$ Over 2.5 million women are currently addicted to drugs in the United States. Worldwide, alcohol use in women has received the widest attention and problems related to illicit substance use and their treatment mirror the issues related to alcohol use in many ways, not minding that important differences may exist. ${ }^{8}$ Studies have also shown that while males consume alcohol to enhance happiness, females consume the same to reduce stress and negativity ${ }^{9,10}$ Women naturally are more sensitive to pain and are likely to experience chronic pain and anxiety, making them more susceptible to abuse of prescribed drugs. ${ }^{11}$ While drug abuse significantly decreased as boys grew older (year-over-year reduction), the same was not seen in girls. ${ }^{12}$ Several reasons exist why women abuse drugs and develop addictions and these are not exclusive to women per se, but are much more prevalent in women than in men. They include self-image issues, sexual abuse and physical abuse. ${ }^{7}$ Gender differences in substance use have been consistently observed in the west, among general population as well as in the treatment-seeking samples, with men exhibiting significantly higher rates of substance use, abuse, and dependence. ${ }^{13,14}$ Women are less likely to seek treatment for drug addictions than men. For many drugs, women are almost twice as likely to become addicted as men and 2 of 3 women's Acquired Immune Deficiency Syndrome (AIDS) cases in the United States involve drugs in some way. ${ }^{7}$ According to National Institute on Drug Abuse (NIDA) ${ }^{15}$ women often use substances differently than men, such as using smaller amounts of certain drugs for less time before they become addicted. Women can respond to substances differently. They may have more drug cravings and may be more likely to relapse after treatment. Also, sex hormones can make women more sensitive than men to the effects of some drugs. However, this gender differences tend to disappear after the age of 50 years. ${ }^{16}$ In a study among female university students aged 18-25 years in India, Kaur et $\mathrm{al}^{17}$ reported that participants used substances out of curiosity, for having fun, personal problems, easy availability, familial use, and health problems. According to an Indian national epidemiologic survey in 2001,7.9\% of women across cities used at least one type of substance. ${ }^{18}$ In the study, heroin, alcohol, cannabis, and painkillers were the dominant substances of abuse. Another part of the survey focusing on women used snowballing sampling technique and reported high rates of opioid and alcohol use in female substance users with an alarming $40 \%$ women reporting lifetime history of Injection drug use. ${ }^{18}$ Though it is hard for anyone to acknowledge the issues with their substance addiction, the stigma of substance addiction, being in denial and the false assumption that if they can still hold a job and take care of house chores, the addiction is under control tends to make women seek intervention late.?

The gap in prevalence rate of substance use is gradually 
closing worldwide. ${ }^{19}$ According to USA surveys, in the 1980s they reported 5:1 male/female ratio of alcohol-use disorders ${ }^{20}$ the ratio dropped to approximately $3: 1$ in a 2007 survey. ${ }^{21}$ In a 2012 study amongst 41.5 million illicit drug users, more than $42 \%$ were women, suggesting a male/female ratio of 1.4:1. ${ }^{22}$ In 2013, the rate of substance dependence among adolescent males was 5.3 percent and their female counterparts was 5.2 percent. ${ }^{23}$ Data from the National Household Survey on Drug Abuse (NHSDA) in 2000 from USA showed that rates of substance use were almost similar between girls and boys in the age groups of $12-17$ years $(9.5 \%$ vs. $9.8 \%)$ and tobacco use was higher in these adolescent girls (14.1\% vs. $12.8 \%$, respectively). ${ }^{12} \mathrm{~A}$ study on substance use in a Nigerian community found a similar incidence rates among males and females $\left(49.1 \%\right.$ and $49.2 \%$ ) respectively. ${ }^{24}$

Comorbid psychological factors have been strongly implicated in women with substance use disorders irrespective of the type of substance used. ${ }^{25}$ Having a comorbid psychiatric diagnosis also increases the chances of women developing a substance use disorder with substance serving as a coping strategy for the mental illness. ${ }^{26}$ Indian studies on treatment-seeking women users have found comorbid depressive disorders in $12 \%$, adjustment disorder in 5\%, somatoform disorder in 3\%, anxiety disorder in $2 \%$, schizophrenia in $2 \%$, obsessive compulsive disorder in $1 \%$ and bipolar affective disorder in $1 \%{ }^{8,27}$ Similarly, from the Indian national Rapid Assessment Survey (RAS study), respondents reported several psychological problems like insomnia, depression, anxiety, suicidal attempts and guilt feelings. ${ }^{8,18}$ The World Health Organization cites that women are two times more likely than men to develop certain mental health conditions like depression, eating disorders, and panic disorders. ${ }^{28,29}$ These disorders, in which women predominate, affect approximately 1 in 3 people in the community and constitute a serious public health problem. ${ }^{29}$ There are no marked gender differences in the rates of severe mental disorders like schizophrenia and bipolar disorder that affect less than $2 \%$ of the population. ${ }^{29}$ Women have lower serotonin levels than men and also process the chemical at slower rates, which can contribute to fluctuations in mood. ${ }^{28}$ Gender differences exist in patterns of help seeking for psychological disorder. Women are more likely to seek help from and disclose mental health problems to their primary health care physician while men are more likely to seek specialist mental health care and are the principal users of inpatient care. ${ }^{29}$ The research has given us a rather detailed overview of psychopathology among women from a generic lens. Also there seems to be a focus on the American and Indian populations. While this is a good first start to using the "funnel approach", the article would read better if the literature was further streamlined to the Nigerian context. The research might uncover patterns and gaps in the literature which would provide better justification and significance to the study.

Quintessential healthcare center, Jos has been attending to clients with general mental illness and substance use disorder both on in-patient and out-patient basis since its inception in 2012. In this retrospective study, we report a five-year profile, drug use and mental illness of women who were admitted into rehabilitation between 2012 and 2017. The review attempts to highlight issues unique to women attending a rehabilitation center. Such knowledge is necessary for developing appropriate services and designing effective treatment. ${ }^{30}$

\section{MATERIALSAND METHODS}

\section{Study location}

The study was conducted at Quintessential Healthcare Center (QHC), Jos South Local government area of Plateau state, Nigeria. The center was established in 2012 with a vision of providing mental health promotion, treatment and rehabilitation for general mental illnesses and substance abuse as well as training and research. QHC offers residential treatment based on therapeutic community model as well as out-patient treatment. Ethical clearance was obtained from the Ethical Committee of Plateau Specialist Hospital for the study and permission by the QHC Management to access data 
from patient's records.

\section{Study population}

All consented female clients with a diagnosis made according to the $10^{\text {th }}$ edition of the International Classification of Diseases (ICD-10) ${ }^{31}$ criteria admitted into the center by the consultant psychiatrists between 2012 and 2017 formed the study population.

\section{Study design}

A retrospective cross-sectional data was collected from the clients' information documented in their case notes.
Information gathered included age, marital status, occupation, educational level, religion, diagnosis, substances used among others. Data was analyzed using SPSS version 22. Descriptive analysis was carried out and chi-square test of significance was used to ascertain relationship between variables. Statistical level of significance was set at $\mathrm{p}<0.05$.

\section{RESULTS}

A total of 183 females were admitted into the facility within the study period comprising 161(88.0\%) Christians and 22(12.0\%) Muslims. Their ages ranged

Table 1 : Sociodemographic Variables

\begin{tabular}{|c|c|c|c|c|}
\hline variable & Groups & Mean & Frequency & $\%$ \\
\hline Age group & $10-19$ & & 58 & 31.7 \\
\hline \multirow[t]{4}{*}{ (years) } & $20-29$ & $38.5(\mathrm{SD}=15.3)$ & 84 & 45.9 \\
\hline & $30-39$ & & 35 & 19.5 \\
\hline & 40 and above & & 6 & 3.3 \\
\hline & Total & & 183 & 100.0 \\
\hline \multirow[t]{2}{*}{ Religion } & Christianity & & 161 & 85.0 \\
\hline & Islam & & 22 & 12.0 \\
\hline \multirow[t]{5}{*}{ Marital status } & Single & & 78 & 42.6 \\
\hline & Married & & 84 & 45.9 \\
\hline & Divorced & & 4 & 2.2 \\
\hline & Separated & & 1 & 0.5 \\
\hline & Widowed & & 16 & 8.7 \\
\hline \multirow[t]{6}{*}{ Occupation } & unemployed & & 27 & 14.8 \\
\hline & Students & & 38 & 20.8 \\
\hline & House wife & & 27 & 14.8 \\
\hline & Traders & & 20 & 10.9 \\
\hline & Nurses & & 10 & 5.5 \\
\hline & Civil servants & & 55 & 30.1 \\
\hline \multirow[t]{7}{*}{ Educational level } & Nil & & 24 & 13.1 \\
\hline & Primary & & 19 & 10.4 \\
\hline & Secondary & & 26 & 14.2 \\
\hline & NCE & & 9 & 4.9 \\
\hline & OND & & 54 & 29.5 \\
\hline & HND & & 6 & 3.3 \\
\hline & Degree & & 45 & 24.6 \\
\hline \multirow[t]{6}{*}{ Year of admission } & 2012 & & 17 & 9.3 \\
\hline & 2013 & & 29 & 15.8 \\
\hline & 2014 & & 36 & 19.7 \\
\hline & 2015 & & 44 & 24.0 \\
\hline & 2016 & & 25 & 13.7 \\
\hline & 2017 & & 32 & 17.5 \\
\hline
\end{tabular}

J Biomed Res. Clin Pract | Vol 4 | No 2 | 2021

For Reprint Contact: jbrcp.net@gmail.com! 
between 12-83 years with a mean age of 38.5 years $(\mathrm{SD}=15.3)$. Almost half, 84(45.9\%) were within the ages of 20-29 years. Nearly half were married $84(45.9 \%)$, educated and employed. (Table 1)

The major diagnosis recorded were depression 66(36.1\%), schizophrenia 58(31.7\%), substance use disorder $31(16.9 \%)$ and bipolar affective disorder $13(17.1 \%)$. Only $27(14.8 \%)$ had a diagnosis of mental illness and substance use disorder (comorbidity) at time of admission. The prevalence of substance use was 50(27.4\%). More than half, 27(14.8\%) of those using/abusing substances used more than one type of substance 23(12.6\%). The major substances abused were alcohol 17(9.3\%), pentazocine 11(6.0\%), cannabis $5(2.7 \%)$, cigarette $5(2.7 \%)$ and benzodiazepines $4(2.2 \%)$. A good number $19(10.4 \%)$ of the studied participants abusing substances were between $20-29$ years. Majority reported commencing substance use within this age bracket. Tramadol and codeine use was relatively low among the study subjects. (Table 2)

Table 2: Diagnosis and Pattern of Substance Use

\begin{tabular}{|c|c|c|c|}
\hline Variable & Groups & Frequency & $\%$ \\
\hline \multirow[t]{9}{*}{ Diagnosis } & schizophrenia & 58 & 31.7 \\
\hline & B.A.D ${ }^{*}$ & 13 & 17.1 \\
\hline & Depression & 66 & 36.1 \\
\hline & SUD $^{* *}$ & 31 & 16.9 \\
\hline & P. $\mathrm{D}^{* * *}$ & 2 & 1.1 \\
\hline & Hyperkinetic disorder & 1 & 0.5 \\
\hline & Autism & 2 & 1.1 \\
\hline & Seizure disorder & 7 & 3.8 \\
\hline & Dementia & 3 & 1.6 \\
\hline \multirow[t]{3}{*}{ Comorbidity } & Yes & 27 & 14.8 \\
\hline & No & 156 & 85.2 \\
\hline & Total & 183 & 100.0 \\
\hline \multirow{3}{*}{ Pattern of substance use } & Single substance & 23 & 12.6 \\
\hline & Multiple substances & 27 & 14.8 \\
\hline & Nil & 133 & 72.7 \\
\hline \multirow[t]{8}{*}{ Main substance of abuse } & Alcohol & 17 & 9.3 \\
\hline & Pentazocine & 11 & 6.0 \\
\hline & Cigarette & 5 & 2.7 \\
\hline & Benzodiazepines & 4 & 2.2 \\
\hline & Cannabis & 5 & 2.7 \\
\hline & Tramadol & 3 & 1.6 \\
\hline & Cocaine & 2 & 1.1 \\
\hline & Codeine & 3 & 1.6 \\
\hline \multirow[t]{4}{*}{ Age at first use } & $10-19$ years & 11 & 6.0 \\
\hline & $20-29$ years & 19 & 10.4 \\
\hline & $30-39$ years & 8 & 4.4 \\
\hline & 40 years and above & 0 & 0.0 \\
\hline
\end{tabular}

J Biomed Res. Clin Pract | Vol 4 | No 2 | 2021 
Majority of those using substances were between the age bracket of $10-19$ years $27(46.6 \%)$. Substance use was absent among the clients aged 40 years and above. A significant association is found between younger age and substance use among the clients studied. (Table 3 )

Table 3: Relationship between age and types of substance used by clients using chi-square

\begin{tabular}{llcllll}
\hline Age in years & \multicolumn{2}{l}{ Pattern of substances used } & NIL & Total & df & P value \\
& Single & Multiple & Substance & & \\
\hline $10-19$ & $11(19.0 \%)$ & $16(27.6 \%)$ & $31(53.4 \%)$ & $58(100.0 \%)$ & 6 & $\mathbf{0 . 0 0 3}$ \\
$20-29$ & $7(8.3 \%)$ & $10(11.9 \%)$ & $67(79.8 \%)$ & $84(100.0 \%)$ & \\
$30-39$ & $5(14.3 \%)$ & $1(2.9 \%)$ & $29(82.9 \%)$ & $35(100.0 \%)$ & \\
40 and above & $0(0.0 \%)$ & $0(0.0 \%)$ & $6(100.0 \%)$ & $6(100.0 \%)$ & \\
\hline
\end{tabular}

\section{DISCUSSION}

A good number of female clients were admitted into the center within the study period. The number admitted per year was relatively stable implying that the turn-up was not subject to variables such as political environment and socioeconomic factors. The center operates a therapeutic community based on Christian doctrine and this can explain the fewer number of Muslim clients compared to the Christian clients. Most of the clients were educated and would likely have given reliable information. Also, all information obtained were corroborated with the family members at admission making the data gathered reliable. From the reported data, a vast majority of the clients were less than thirty years. These represent the productive age range of the society implying a high rate of economic loss due to mental health conditions.

More subjects were admitted for other mental disorders than for substance use disorder. Depression was the leading diagnosis followed closely by schizophrenia and bipolar disorders in that order. This is similar with other studies $^{28,32}$ that recorded depression as the commonest diagnosable mental disorder among females and as a silent cause of mortality and morbidity among women. Few women actually presented with comorbid mental illness and substance use disorder 27(14.8\%) suggesting that primary mental illness may not be a significant cause of substance use among females.

Alcohol was the most used substance among the participants. This is in agreement with other hospitalbased studies ${ }^{33}$ but differed from results of surveys that reported cannabis as the most abused substance. ${ }^{3,4}$ Within Nigeria, alcohol is legal and it is culturally accepted and readily available within the environment of the study in various forms. This could explain the higher rate of alcohol abuse relative to other substances in the study. Pentazocine use was equally high among the studied participants. However, tramadol and codeine which are illicit substances were not highly abused among the participants. Difficulty in accessing these substances could be responsible for the low prevalence.

\section{CONCLUSION}

This enquiry into the issues unique to women attending a rehabilitation center in Nigeria found that among females, substance use is a younger age affair. More females enter rehabilitation for severe mental illness than for substance 
use disorder. The study also found that females abuse multiple substances and this portrays significant health and economic consequences to the female gender.

\section{Recommendation}

We recommend a prospective study to evaluate factors associated with use of substances among females entering rehabilitation.

\section{Acknowledgment}

We acknowledge the permission of the management and staff of Quintessential Healthcare Center in assessing the data of the clients studied.

\section{REFERENCES}

1. Nock NL, Minnes S, Albets JL. Neurobiology of substance use in adolescents and potential therapeutic effects of exercise for prevention and treatment of substance use disorders. HHS Public Access 2017;109(20):1711-1729. doi 10.1002/bdr2.1182. PMC 5751741. PMID: 29251846.

2. Lenoue SR, Riggs PD. Substance Abuse Prevention. Child AdolescPsychiatr Clin N. Am. 2016; 25:297-305.

3. UNODC. Drug use survey in Nigeria 2018. Available online at https://www.unodc.org/documents/data-andanalysis/statistics/Drugs/. Accessed on $28^{\text {th }}$ of April, 2021.

4. UNODC, World Drug Report 2010. Understanding the extent and nature of drug use. Available online at https://www.unodc.org. Accessed on $25^{\text {th }}$ of April 2021.

5. Gordon SM, Research and Professional Training Caron Foundation \& Addiction: Gender Issues in Abuse and Treatment, 2002, http://www.caron.org/.

6. Carter CS. Ladies don't: A Historical perspective on attitudes toward alcoholic women. Affilia 1997; 12:471-85.
7. Drug abuse treatment for women. Available online at https://www.michaelshouse.com/drugabuse/treatment-women/ Accessed on $25^{\text {th }}$ April 2021.

8. Lal R, Deb KS, Kedia S. Substance use in women: Current status and future directions. Indian J Psychiatry 2015; 57:275-85.

9. Becker JB, Hu M. Sex Differences in Drug Abuse. Front Neuroendocrinol. 2008;29(1):36-47.

10. Greenfield SF, Back SE, Lawson K, Brady KT. Substance Abuse in Women. Psychiatr Clin North Am. 2010;33(2):339-55.

11. NIDA. 2021, April 13. Sex and Gender Differences in Substance Use. Retrieved from https://www.drugabuse.gov/publications/researchreports/substance-use-in-women/sex-genderdifferences-in-substance-use on 2021, April 28

12. NHSDA. Substance Abuse and Mental Health Services Administration. Summary of findings from the 2000 National Household Survey on Drug Abuse. Rockville, MD: Office of Applied Studies; 2001.

13. Kessler RC, Chiu WT, Demler O, Merikangas KR, Walters EE. Prevalence, severity, and comorbidity of 12-month DSM-IV disorders in the National Comorbidity Survey Replication. Arch Gen Psychiatry 2005; 62:617-27.

14. Compton WM, Thomas YF, Stinson FS, Grant BF. Prevalence, correlates, disability, and comorbidity of DSM-IV drug abuse and dependence in the United States: Results from the national epidemiologic survey on alcohol and related conditions. Arch Gen Psychiatry 2007; 64:566-76.

15. NIDA. 2020, January 22. Substance Use in Women DrugFacts. Retrieved from https://www.drugabuse.gov/publications/drugfacts/s ubstance-use-in-women on 2021, April 25.

16. Seitz HK, Egerer G, Simanowski UA, Waldherr R, Eckey R, Agarwal DP, et al. Human gastric alcohol dehydrogenase activity: Effect of age, sex, and alcoholism. Gut 1993; 34:1433-7. 
17. Kaur R, Sing T, Basu D, Kumar R. Prevalence and pattern of psychoactive substance use among female students aged 18-25 years in universities of North India. Int J Community Med Public Health. 2019;6(2):602-609.

18. Ray R, Mondal AB, Gupta K, Chatterjee A, Bajaj P. The Extent, Pattern and Trends of Drug Abuse in India: National Survey. New Delhi: United Nations Office on Drugs and Crime, Regional Office for South Asia and Ministry of Social Justice and Empowerment, Government of India; 2004.

19. Grucza RA, Norberg K, Bucholz KK, Bierut LJ. Correspondence between secularchanges in alcohol dependence and age of drinking onset among women in the United States. Alcohol Clin Exp Res 2008; 32:1493-501.

20. Helzer J, Burnam A, McEvoy L. Alcohol abuse and dependence. In: Robins L, Regier D, editors. Psychiatric Disorders in America: The Epidemiological Catchment Area Study. New York: The Free Press; 1991.p. 81-115.

21. Hasin DS, Stinson FS, Ogburn E, Grant BF. Prevalence, correlates, disability, and comorbidity of DSM-IV alcohol abuse and dependence in the United States: Results from the National Epidemiologic Survey on Alcohol and Related Conditions. Arch Gen Psychiatry 2007; 64:830-42.

22. McHugh RK, Wigderson S, Greenfield SF. Epidemiology of substance use in reproductive-age women. ObstetGynecol Clin North Am 2014;41:177-89.

23. Peiper NC, Ridenour TA, Hochwalt B, CoyneBeasley T. Overview on Prevalence and Recent Trends in Adolescent Substance Use and Abuse. Child AdolescPsychiatr Clin N. Am. 2016; 25:349-365.

24. Nwoga CN, Ndak AZ, Audu MD, Goar SG, Armiya'u AY, Agbir TM et al. Pattern and Effect of Substance Use in Jos South, North Central Nigeria. Journal of Research in Basic \& Clinical Sciences.
2019;1(2):150-154.

25. Brown C, Madden PA, Palenchar DR, Cooper-Patrick L. The association between depressive symptoms and cigarette smoking in an urban primary care sample. Int J Psychiatry Med 2000; 30:15-26.

26. Ullman SE, Relyea M, Peter-Hagene L, Vasquez AL. Trauma histories, substance use coping, PTSD, and problem substance use among sexual assault victims. Addict Behav 2013; 38:2219-23.

27. Nebhinani N, Sarkar S, Gupta S, Mattoo SK, Basu D. Demographic and clinical profile of substance abusing women seeking treatment at a de-addiction center in North India. Ind Psychiatry J 2013;22:12-6.

28. Common Mental Health Issues Among Women. Dual Diagnosis available online at . Accessed on 1st may 2021.

29. WHO. Gender and women's mental health. Available online at http://www.who.int/mental_health/prevention/gende rwomen/en/ Accessed on $1^{\text {st }}$ May, 2021.

30. Wilsnack S, Wilsnack R. International Gender and Alcohol Research: Recent Findings and Future Directions [Internet]. NIAAA; 2003. Available from: http://pubs.niaaa.nih.gov/publications/arh264/245-250.htm. [Accessed on 2021 April 25].

31. The ICD-10 Classification of Mental and Behavioural Disorders. Clinical description and diagnostic guidelines. World Health Organization 1992, Geneva.

32. Stewart DE, Ashraf IJ, Munce SE. Women's mental health: A silent cause of mortality and morbidity. International Journal of Gynecology and Obstetrics 2006; 94, 343 - 349.

33. Audu MD, Bankat MA, Enejoh V. High risk sexual behaviour among non-injecting drug users in Jos, Nigeria. African Journal of Applied Psychology 2009;3,:72-79. 